\title{
Faculty of Dentistry, Kuwait University, Designated as a World Health Organization Collaborating Centre for Primary Oral Health Care
}

\author{
J.M. Behbehani \\ Department of Restorative Sciences, Faculty of Dentistry, Kuwait University Health Sciences Centre, Jabriya, Kuwait
}

\author{
Key Words \\ Primary health care $\cdot$ Oral epidemiology $\cdot$ Oral health . \\ Preventive dentistry
}

\begin{abstract}
The Faculty of Dentistry, Kuwait University, was designated as a World Health Organization (WHO) Collaborating Centre for Primary Oral Health Care (POHC) in 2011. This article aimed to describe the following: (1) the background for this nomination, (2) the WHO Collaborating Centre for POHC, its terms of reference and 5 activities, (3) the primary health care concept as it was established in Alma-Ata, (4) the oral health situation in Kuwait and in the Middle-East region and, finally, (5) how POHC policy should be implemented in Kuwait and this region. It can be concluded that, because the caries experience is very high in Kuwait and in the other countries of the Eastern Mediterranean region, good $\mathrm{POHC}$ programmes should be designed and implemented in this region. The Faculty of Dentistry will strengthen its research tradition and as a WHO Collaborating Centre for POHC will try to collect information and experience from $\mathrm{POHC}$ in this region and exchange ideas between $\mathrm{POHC}$ experts in this region on how these programmes could be further developed. This will happen according to the terms of reference and activity plans of the WHO Collaborating Centre for $\mathrm{POHC}$ approved by the WHO Global Oral Health Programme.
\end{abstract}

(c) 2014 S. Karger AG, Basel

\begin{tabular}{ll}
\hline KARGER & $\begin{array}{l}\text { ( } 2014 \text { S. Karger AG, Basel } \\
1011-7571 / 14 / 0237-0010 \$ 39.50 / 0\end{array}$ \\
$\begin{array}{l}\text { E-Mail karger@karger.com } \\
\text { www.karger.com/mpp }\end{array}$ & $\begin{array}{l}\text { This is an Open Access article licensed under the terms of the } \\
\text { Creative Commons Attribution-NonCommercial 3.0 Un- } \\
\text { ported license (CC BY-NC) (www.karger.com/OA-license), } \\
\text { applicable to the online version of the article only. Distribu- } \\
\text { tion permitted for non-commercial purposes only. }\end{array}$
\end{tabular}

\section{Introduction}

The Faculty of Dentistry, Kuwait University, was designated as a World Health Organization Collaborating Centre (WHOCC) for Primary Oral Health Care (POHC) in 2011 [1]. This WHOCC is located in the Eastern Mediterranean Region of the WHO. There are altogether 20 WHOCCs operating under the WHO Global Oral Health Programme. This nomination of the Faculty was based on the long-term cooperation by the Ministry of Health, $\mathrm{Ku}$ wait and later on by the Faculty of Dentistry, Kuwait University, with the WHO Oral Health Programme Headquarters, Geneva. This article aimed to describe the following: (1) the background for this nomination, (2) the WHOCC for POHC, its terms of reference and 5 activities, (3) the primary health care (PHC) concept as it was established in Alma-Ata, (4) the oral health situation in Kuwait and in the Middle-East region and, finally, (5) how POHC policy should be implemented in Kuwait and this region.

\section{Background of the Faculty of Dentistry}

The Faculty of Dentistry was founded at the Kuwait University by an Amiri decree in 1996, the first batch of 26 students was admitted in 1998, and the first academic staff was recruited in 1998. The first research grant for the Faculty was submitted to Kuwait University in 1999. Currently, the Faculty has 18 ongoing research projects and

Dr. Jawad M. Behbehani

Department of Restorative Sciences

Faculty of Dentistry, Kuwait University

PO Box 24923, Safat 13110 (Kuwait)

E-Mail jawad.behbehani@hsc.edu.kw 
Fig. 1. The number of IADR members in the AMER in December 2012. UAE = United Arab Emirates.
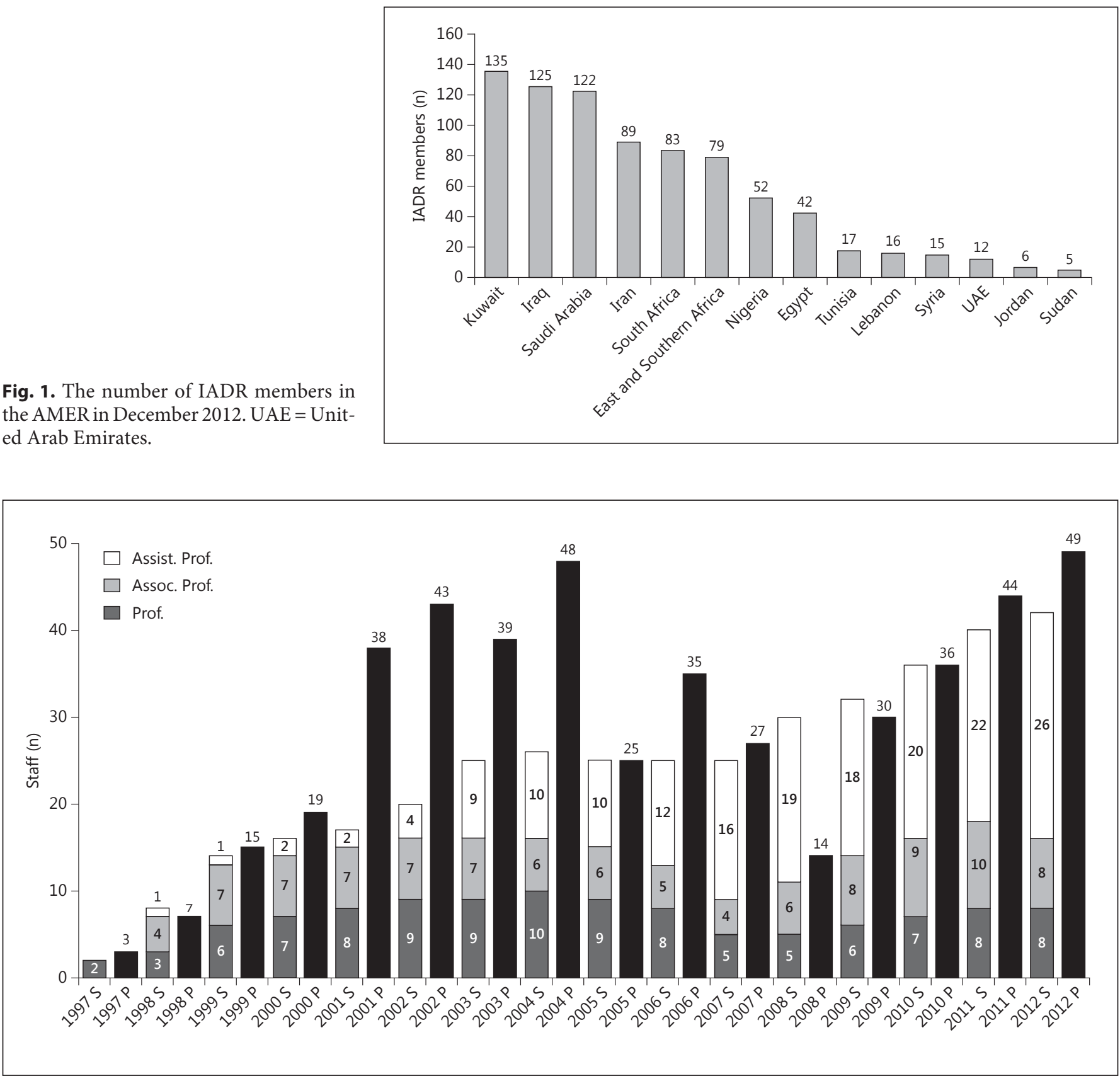

Fig. 2. The development of academic staff of the Faculty of Dentistry (year + staff; staff includes professors + associate professors + assistant professors) and the number of scientific publications (year + publications) in 19972012. $S$ = Staff; $P$ = publications.

altogether 62 projects, which have been funded by Kuwait University. About half of all projects have public health relevance.

The Kuwait Association for Dental Research (KuADR) was established as a Section of the International Association for Dental Research (IADR) in 2000. The Kuwaiti
IADR Section was upgraded to Division in 2003. The African and Middle-East Region (AMER) of the IADR was established (as a Federation at the beginning), in the same year. Membership of the KuADR has gradually increased and it was the highest among the IADR Divisions/Sections in this AMER region in 2012 (fig. 1). 
Table 1. Faculty of Dentistry, WHOCC for POHC, terms of reference [1]

(1) to assist WHO ORH in identifying countries around the globe that have established POHC programmes and analysis of programme components included for the provision of oral health care and oral health promotion

(2) to assist WHO ORH in the assessment of the practical experiences and relevance of using primary health workers and ancillary oral health personnel in low-resource communities

(3) to assist WHO ORH in the development of appropriate models for POHC applicable to low-, middle- and high-income countries

(4) to assist WHO ORH in the development of guidelines for essential care to countries/communities based on the evidence available and practical experience

(5) to support the development of surveillance systems for the assessment of outcomes of POHC and school-based oral health promotion

(6) to assist WHO ORH in the orientation of oral health systems towards health promotion, with emphasis on provision of evidencebased intervention and practical community approaches in oral health promotion and oral disease prevention

(7) to promote the global development of the Health Promoting Schools Initiative through the establishment of school-based oral health promotion in the African and Middle-East countries

(8) to assist WHO ORH in the translation of scientific knowledge for oral health intervention and bridging the gap in research between the developing and developed countries

WHO ORH = WHO Global Oral Health Programme.

The Faculty of Dentistry started to arrange international conferences very soon after the establishment. The 1st international conference of the Faculty was arranged in 1999 with the theme 'Minimal Intervention Approach for Dental Treatment'. It was funded by the Kuwait Foundation for Advancement of Sciences and the Academy of Finland. The proceedings of this first Faculty of Dentistry conference were published in 2002 as the first supplement of Medical Principles and Practice [2]. The 1st KuADR conference was arranged in 2001 with the theme 'Evidence-Based Practice in Dentistry'. The proceedings of this conference were also published in the Medical Principles and Practice supplement [3] in 2003. The 2nd KuADR conference in 2002 was a joint conference with the Kuwait Dental Association, because Kuwait University has had a policy to support the international conferences of all faculties (14) every second year. The 3rd KuADR conference was arranged in 2003 with the theme 'Oral Health in the Eastern Mediterranean and African Regions'. The proceedings of this conference were published in the International Dental Journal supplement [4] in 2004. The 4th KuADR conference was a joint conference, this time with the Eastern and Southern African IADR Division in Nairobi, Kenya, in 2004. The 5th KuADR conference was also the 1st AMER conference of the IADR, in Kuwait, in 2005. This was the biggest dental research conference ever organized in Kuwait with 267 submitted abstracts altogether. The 6th KuADR confer- ence was again a joint conference, this time with the European Association of Dental Public Health, in Prague, Czech Republic, in 2006. The 7th KuADR conference was in 2007, and the 8th KuADR conference was arranged for the IADR Colgate Hatton competition for students, in 2008. The 9th KuADR conference was again a joint conference with the 2nd AMER conference, in Mombasa, Kenya, in 2009. The 10th conference had a theme 'Preventive and Minimal Intervention Dentistry', in 2010. The proceedings of this conference were published as a Journal of Dentistry supplement [5], in 2011. The 11th KuADR conference was a joint one, with the 3rd AMER conference, in Abuja, Nigeria, in 2011. The 12th conference, in 2012, was arranged also to inaugurate the designation of the Faculty as a WHOCC for POHC, which had happened in 2011. The second day of the conference was devoted to the AMER and it was the first AMER council meeting with the quorum (over $50 \%$ present), when altogether 10 from 14 IADR Divisions/Sections had their representatives at this meeting. The annual international conferences reflect the heavy emphasis on research by the Faculty. The scientific publications by the Faculty staff have also increased quite rapidly along with the increasing number of academic staff, especially the senior staff (fig. 2). About one third of the publications are in the domain of public health. The active research has also been recognized by the WHO, which nominated the Faculty as a WHOCC for POHC.
Behbehani 


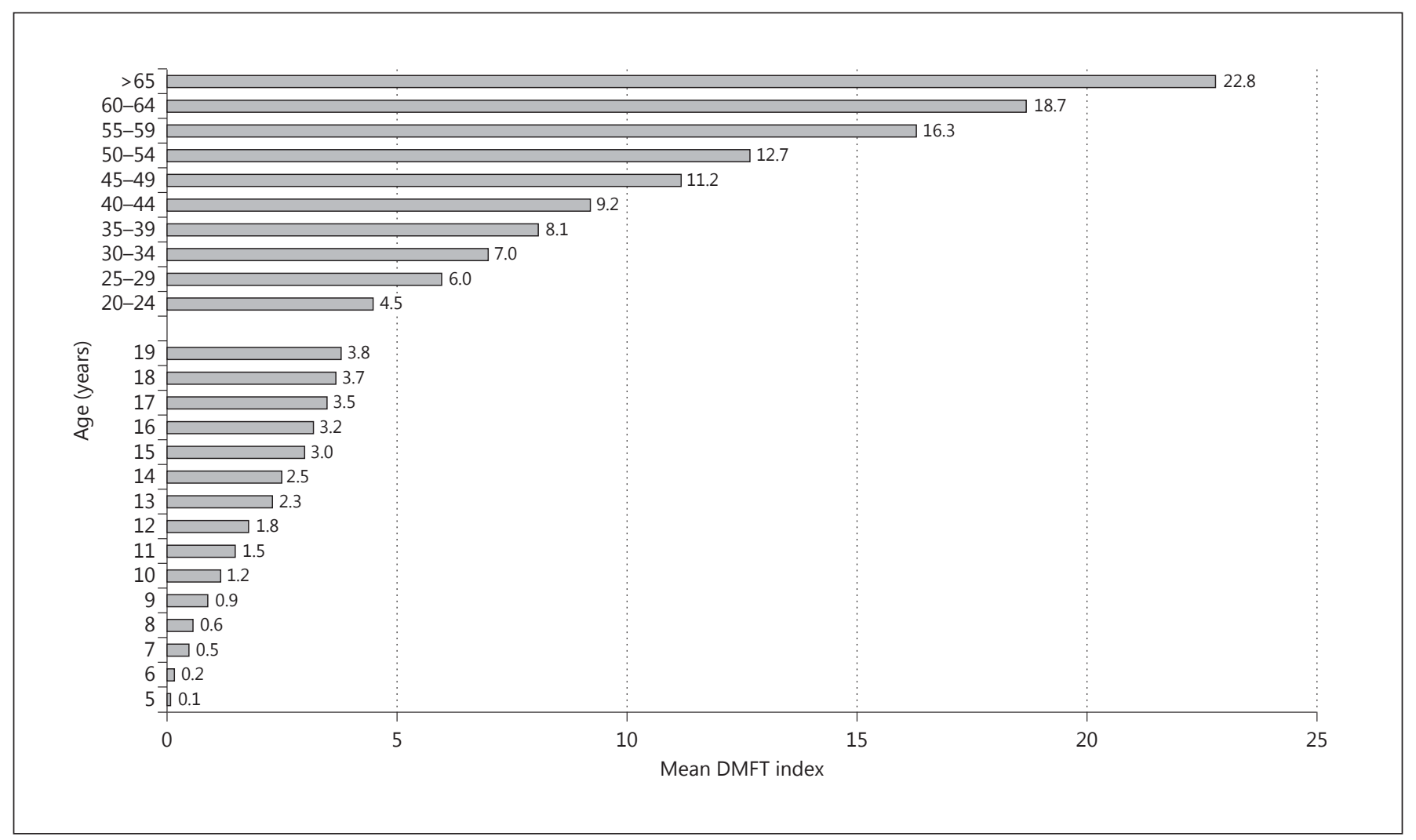

Fig. 3. The mean DMFT index according to age in Kuwait [data from 2].

\section{WHOCC for POHC}

The terms of reference for our WHOCC for POHC give the framework for the centre and they were defined in the designation document [1] (table 1). In relation to the terms of reference this WHOCC also has the following activities in its first 5-year plan [1]: (1) implementation of policies and programmes for oral health promotion and integrated disease prevention according to WHA60.17 [2] (responsible coordinator: Dr. Jawad M. Behbehani), which is described in this article, (2) surveys of health behaviour of schoolchildren for establishing national surveillance according to WHO approaches, (3) establishing oral health/health promoting schools in Africa and the Middle-East (responsible coordinator: Dr. Sisko Honkala; see separate article in this supplement), (4) appropriate POHC models for countries with different levels of economic development and (5) evidence-based approach on models of POHC (responsible coordinator: Prof. Eino Honkala; see separate article in this supplement).

WHO Collaborating Centre for Primary Oral Health

\section{PHC Concept}

$\mathrm{POHC}$ is an integral part of $\mathrm{PHC}$ and it is based on the original PHC definition by the Alma-Ata conference [6] in 1978: 'Primary health care is essential health care, based on practical, scientifically sound and socially acceptable methods and technology, made universally accessible to individuals and families in the community through their full participation and at a cost that the community and country can afford to maintain at every stage of their development in the spirit of self-reliance and self-determination'. This is still the most comprehensive definition of $\mathrm{PHC}$ and describes what PHC actually means in this global world. The Alma-Ata conference also defined that 'health is a fundamental human right and worldwide social goal' and stated that the 'health of hundreds of millions of people in the world is unacceptable!' The conference also demanded 'equitable distribution of health resources for gaining health for all citizens of the world'. The 5 main principles of PHC at the Alma-Ata conference were defined as follows: (1) equitable distribution of 


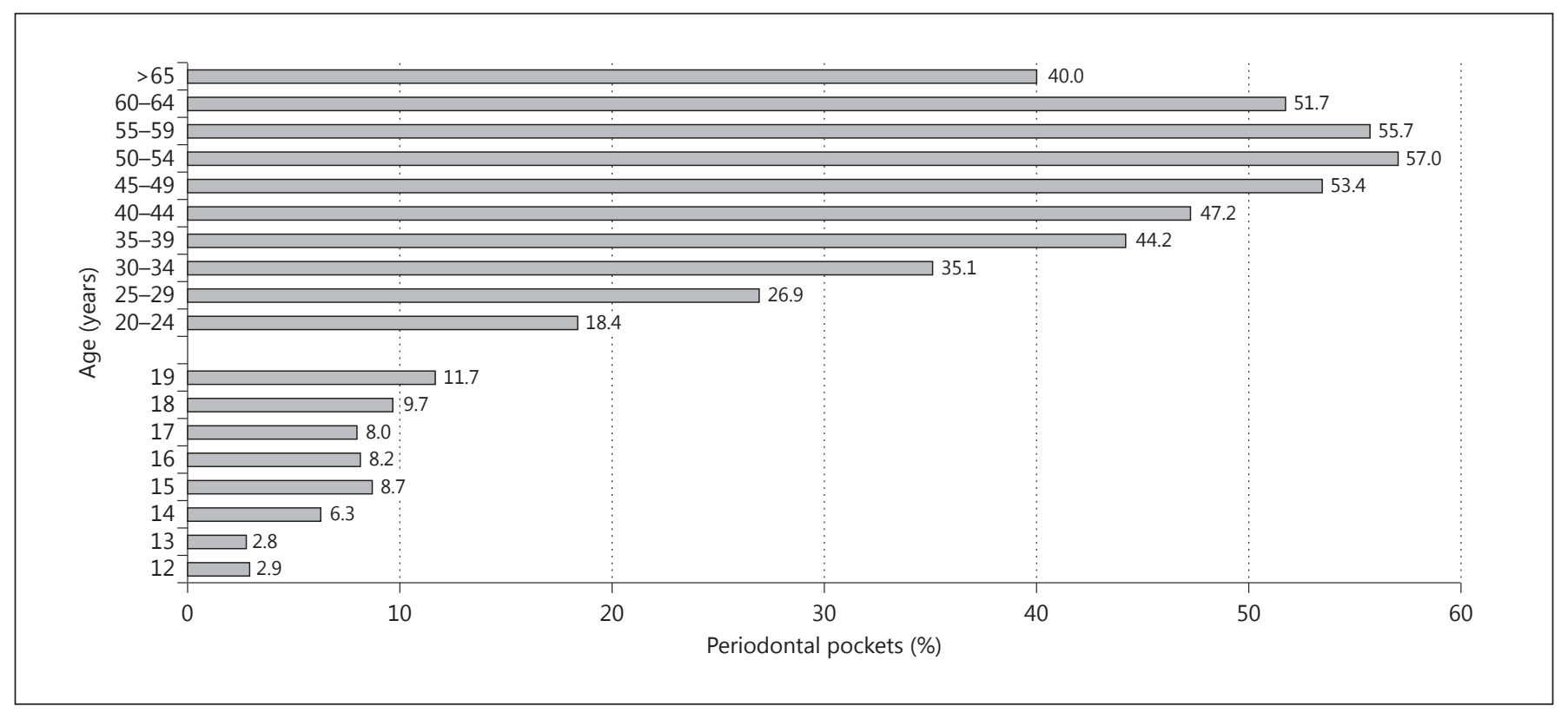

Fig. 4. The prevalence of periodontal pockets according to age in Kuwait [data from 2].

health care services, (2) community involvement, (3) focus on prevention, (4) appropriate technology and (5) multisectorial approach. These principles also concern $\mathrm{POHC}$ and they are still valid after 3 decades. The current understanding of $\mathrm{PHC}$ was redefined in the World Health Report: 'Primary Health Care - Now More than Ever' in 2008 [7]. This report states that 'people have a right to the highest attainable level of health, maximizing equity and solidarity, while being guided by responsiveness to people's needs'. According to this World Health Report 2008, PHC requires 4 main reforms: (1) universal coverage, (2) service delivery, (3) public policy and (4) leadership reforms. Universal coverage reform is based on the equity principle of the Alma-Ata, service delivery reform should be based on the needs and demands of the people, public policy reform should promote and protect the health of communities and make the environment healthy and, finally, leadership reform should make the leaders more responsible for people [7].

\section{Oral Health in Kuwait}

The main concern of the WHOCC for POHC obviously is the oral health of the population in Kuwait and in the Middle-East region. There is only one populationbased survey including the total population conducted in
Kuwait, the Kuwait Health Survey, which also included clinical oral examinations. The original data were collected in 1984-1985 and the sample consisted of 3,358 households and 26,530 individuals representing $1.6 \%$ of all people residing in Kuwait in 1984. Interviews and oral examinations were carried out for 17,906 individuals. The results were never published because the original data (magnetic tapes) were destroyed during the Iraqi invasion of Kuwait. The descriptive results of oral health were published 15 years after the survey [8], when the hard copies of the frequency distributions were found by the Ministry of Health. No statistical testing was possible, because the subject-based data were not available. However, the huge sample size allowed very reliable estimates from the population of Kuwait. In this cross-sectional data, the caries experience (number of decayed, missing or/and filled teeth, DMFT) increased consistently according to age from 0.1 (5-year-olds) to 22.8 ( $\geq 65$-year-olds; fig. 3 ). Nonetheless, it should be acknowledged that the caries assessment for the age groups above 35-40 years old cannot be considered reliable because of the increasing effect of the M-component for DMFT. Caries prevalence (DMFT $>0$ ) also increased from $2.7 \%$ (5-year-olds) to 95.9\% (60- to 64-year-olds) and then slightly declined in the older age groups with the declining number of teeth among $\geq 65$-year-olds [8]. The prevalence of periodontal pockets $(>3 \mathrm{~mm})$ increased from $0.1 \%$ (12-year-olds) to 


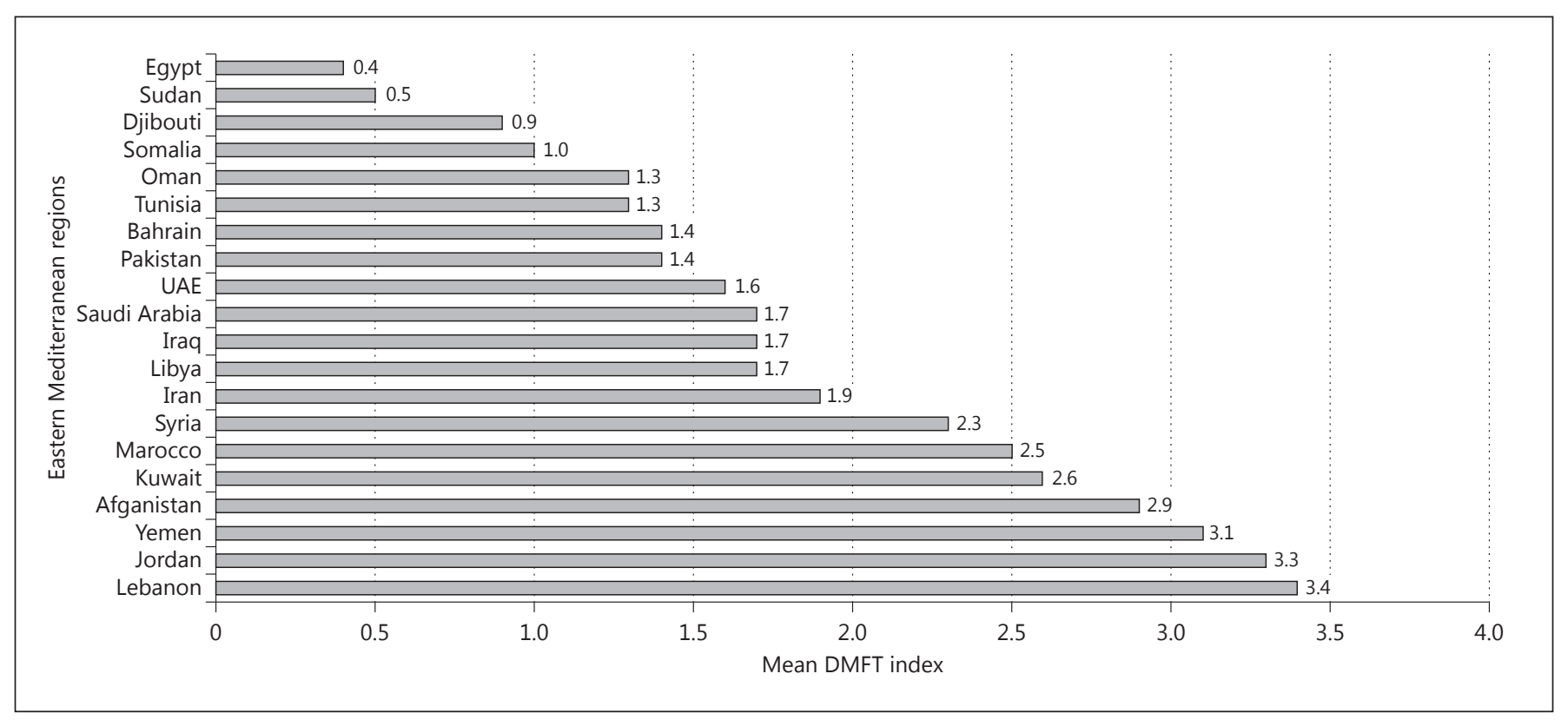

Fig. 5. The mean DMFT index at the age of 12 in the Eastern Mediterranean region [data from 10]. UAE = United Arab Emirates.

Table 2. World Health Assembly (WHA60.16) recommendations to member states [13]

(1) to ensure that oral health is incorporated into policies for the integrated prevention and treatment of chronic non-communicable and communicable diseases, and into maternal and child health policies

(2) to ensure that evidence-based approaches are used

(3) to provide coverage of the population with essential oral health care, and to incorporate oral health into the framework of enhanced $\mathrm{PHC}$

(4) for those countries without access to optimal levels of fluoride, and which have not yet established systematic fluoridation programmes, to consider the development and implementation of fluoridation programmes, giving priority to equitable strategies such as the automatic administration of fluoride, e.g. in drinking-water, salt or milk, and to the provision of affordable fluoride toothpaste

(5) to ensure that prevention of oral cancer is an integral part of national cancer control programmes

(6) to ensure the prevention of oral disease associated with HIV/AIDS, and the promotion of oral health and quality of life for people living with HIV

(7) to develop and implement the promotion of oral health and prevention of oral disease for pre-school and schoolchildren as part of activities in health-promoting schools

(8) to scale up capacity to produce oral health personnel, including dental hygienists, nurses and auxiliaries

(9) to develop and implement, in countries affected by noma, national programmes to control the disease

(10) to incorporate an oral health information system into health surveillance plans

(11) to strengthen oral health research and use evidence-based oral health promotion and disease prevention

(12) to address human resources and workforce planning for oral health as part of every national plan for health

(13) to increase the budgetary provisions dedicated to the prevention and control of oral and craniofacial diseases

(14) to strengthen partnerships and shared responsibility among stakeholders in order to maximize resources in support of national oral health programmes

57\% (50- to 54-year-olds) and then also declined in the oldest age groups, when less teeth were retained in the mouth (fig. 4). The age distribution of the population in Kuwait is considerably different among the Kuwaiti and the non-Kuwaiti population groups, because the middle age groups (20-54 years) are over-represented in the nonKuwaiti population [9]. The trends of caries experience can be estimated from the different cross-sectional child oral health surveys with WHO methods conducted between 1982 and 2000 in Kuwait, which show that no de- 
clining trend exists. The two recent surveys by the Kuwait National School Oral Health Programme unfortunately confirm the same trend [9-11]. In general, caries experience is very high in Kuwait and in the other countries of the Eastern Mediterranean region (fig. 5) [11].

\section{POHC Policy}

The World Health Assembly had its first meeting on oral health in 2007, acknowledging the link between oral health, general health and quality of life, and emphasizing the need to incorporate programmes for the promotion of oral health and the prevention of oral diseases into programmes for the integrated prevention and treatment of chronic diseases [12]. This meeting also had a comprehensive list of actions on POHC. The World Health Assembly stated that it urges member states to follow these recommendations (table 2). Oral health promotion in Kuwait is part of the health promotion national strategy (see separate article of Dr. Kazem Behbehani in this supplement). Water fluoridation was also one recommendation which has been emphasized in Kuwait [13]. Water fluoridation had already been implemented in Kuwait, but ceased in 1984. The pre-school and schoolchildren are covered by the Kuwait National School Oral Health Programme (see the article of Dr. Jitendra Ariga in this supplement). Efforts are required to get education of den- tal hygienists re-started in the Public Authority of Applied Education and Training. The research policy [14] of the Faculty of Dentistry consisted of: (1) biomedical research, (2) clinical research and (3) dental research. It is also expected that $\mathrm{POHC}$ research will be strengthened by the Faculty of Dentistry and the WHOCC for POHC.

\section{Conclusion}

Because the caries experience is very high in countries of the Eastern Mediterranean region, good POHC programmes should be designed and implemented in this region. The Faculty of Dentistry will strengthen its documented research policy and as a WHOCC for POHC will try to collect information and experience from this region and exchange ideas between $\mathrm{POHC}$ experts in the region on how these programmes could be further developed. Effective POHC programmes should be designed and implemented in this region. This will happen according to the terms of reference and 5 activities approved for WHOCC for POHC by the WHO Global Oral Health Programme.

\section{Disclosure Statement}

The author discloses no conflicts of interest.

\section{References}

1 WHO: Designation Form: Faculty of Dentistry, Kuwait University. WHO Collaborating Centre for Primary Oral Health Care. WHO, 2011.

2 Behbehani JM, Honkala E (eds): Proceedings of the International Conference on Minimal Intervention Approach for Dental Treatment. Med Princ Pract 2002;11(suppl 1):54.

3 Behbehani MJ, Honkala E (eds): Proceedings of the International Conference on EvidenceBased Practice in Dentistry. Med Princ Pract 2003;12(suppl 1):65.

$\checkmark 4$ Behbehani JM, Honkala E (eds): Proceedings of the International Conference on Oral Health in the Eastern Mediterranean and African Regions. Int Dent J 2004;54(suppl 1):327-410
5 Behbehani JM, Honkala E (eds): Proceedings of 'The International Conference on Preventive and Minimal Intervention Dentistry'. J Dent 2011;39(suppl 2):S1-S55.

6 WHO: Primary Health Care. Report of the International Conference on Primary Health Care, Alma-Ata, USSR, September 6-12, 1978. Health for All Series No 1, WHO, 1978, pp 79.

7 WHO: World Health Report 2008 - Primary Health Care - Now More than Ever. WHO, Geneva, 2008.

$>8$ Behbehani JM, Shah NM: Oral Health in Kuwait before the Gulf War. Med Princ Pract 2002:11(suppl 1):36-43.

$\checkmark 9$ Behbehani JM, Scheutz F: Oral health in Kuwait. Int Dent J 2004;54(suppl 1):401-408.
10 WHO: Global Oral Health Data Bank. http:// www.mah.se/CAPP/Country-Oral-HealthProfiles/EMRO/ (accessed May 15, 2013).

-11 Al-Mutawa SA, Shyama M, Al-Duwairi Y, Soparkar P: Dental caries experience of $\mathrm{Ku}-$ waiti schoolchildren. Community Dent Health 2006;23:31-36.

12 WHO: Oral health: action plan for promotion and integrated disease prevention. WHA.60.16. http://apps.who.int/gb/ebwha/ pdf_files/WHA60/A60_16-en.pdf.

13 Research Directorate, Kuwait Foundation for Advancement of Sciences. Fluorides and Oral Health Symposium, December 11-13, 2006. KFAS, 2006, pp 156.

14 Faculty of Dentistry, Research Policy. Kuwait University Press, 2001, pp 19. 